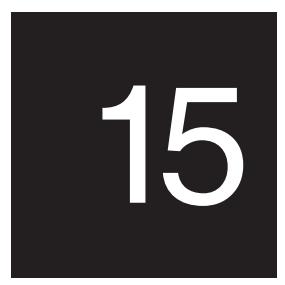

\title{
Vaka Moana-a road map for the South Pacific economy
}

\section{Hana Ayala}

The long-term impact of UNESCO's World Decade for Cultural Development 1988-97 is shaped by the timeliness of this endeavour. As an antidote to the globalisation megatrend, which is often marked by cultural homogenisation, the World Decade has encouraged interdisciplinary and inter-agency approaches that emphasise the rich contributions of cultural diversity to resource conservation and the sustainable growth of a progressively globalising economy. I believe that there exists, in the target regions of Mundo Maya, Silk Road, and Vaka Moana, an outstanding opportunity to align the Decade's spirit and achievements with the economic aspirations that the regions' governments increasingly entrust to the promise of tourism. The ever stronger heritage orientation of international leisure travel resonates remarkably well with the heritage bias of the World Decade, notwithstanding differences in motivation, humanistic for UNESCO, and business-oriented for the tourism industry. The boom in heritage tourism gives a forceful economic connotation to the World Decade's legacy and sets the stage for shifting the focus of its implementation from correcting economic development to driving it. My proposal for employing Vaka Moana as a catalyst for the South Pacific economy provides a sequel to the World Decade that would accomplish this shift in focus. 


\section{The paradigm of international ecotourism}

International tourism and international ecotourism are irreversibly merging. The majority of international leisure travellers are 'soft' ecotourists: 'ecotourists' because of their demand for an authentic and enriching experience of nature and culture as well as their willingness to contribute to conservation, and 'soft' because of their overwhelming preference for high standards of accommodation, service, and security. Market data from Central America fully confirm this trend. 'Hard' or 'pure' ecotourists, who are willing to sustain low comfort levels and utilise minimal facilities, represent only a small number of tourists who visit the region's protected areas, and their proportion diminishes every year (Ashton 1993).

It is not just the accommodation element of heritage-centred tourism that entails a great amount of investment, in terms of both capital and technical expertise. The interpretive infrastructure poses no less of a challenge. International leisure travellers have increasingly higher expectations of the quality of information concerning the nature and culture of their destinations, regarding both the content and presentation (Ayala 1995a). This contrasts sharply with the common, but false belief particularly widespread among governments and developers in island countries, that nature-or other heritagebased tourism-is an excellent way to attract tourists with little initial capital expenditure (Bookman 1994).

Cooperation is emerging as another challenge for heritage destinations. Evolution, history, ecology, and other relationships that bond natural and human ecosystems allow the tourism industry to combine multiple destinations into heritage themes whose aggregate identity and eminent marketability enhance the heritage value of each participating destination. As international leisure tourism progressively redefines itself into heritage tourism, competition unfolds among national and regional heritage packages. The World Tourism Organization (WTO) supports this idea through its involvement in some fifty countries across Europe and Asia that participate in the Silk Road project as a new destination (WTO News 1994). This composite destination is not to be travelled all in one trip, but lends a powerful heritage context to any sub-destination, be it a gateway city of Tashkent or Istanbul, or a nature reserve in China's Xinjiang (Tang 1991). The same principle applies for Mundo Maya, the umbrella theme that spans a splendid cultural and landscape heritage across 
five Latin American countries, and for Paseo Pantera, a multi-country initiative that envisions the proposed Central American Biological Corridor as the backbone of the Central American heritage product.

The more international tourism transforms itself into heritage tourism, the less viable and manageable it becomes as a sectoral activity. The international tourism and hotel industry needs access to knowledge about the destination's nature and culture in order to provide interpretive guidance for the heritage experience. Generating such knowledge is not within the industry's expertise. It is, however, within the industry's capacity and business interest to mobilise others to generate such knowledge. Further, the resources that support the heritage experience and, thus, decisively condition the business value of the tourist enterprise are not owned or managed by the industry, but by indigenous peoples and conservation authorities among others. That confronts the industry with the need to engage in partnerships to guarantee product quality, which opens a major - so far largely untapped-opportunity for indigenous and local people to benefit from international tourism by assuming responsibility for sustainable resource management. When cultural experience derives from intangible attractions, such as sacred values, rituals and beliefs, the indigenous or local management of the experience in the presence of tourists helps ensure the viability of the tourist enterprise, since it greatly increases the tourists' satisfaction and sense of participation (Sofield 1991).

The proliferation of national and regional development plans that single out heritage tourism as a new priority for economic growth, creates a unique circumstance for realising the potential of international tourism and the hotel industry to become, globally, the strongest sponsor of conservation. This scenario pertains to both natural and cultural conservation. The prospect of transforming the industry into an important benefactor of research on natural and human ecosystems is attainable because of the boom in heritage tourism. The value of such research is not limited to tourism, but spills over into agriculture, education, health, and other sectors of the host country's economy. There are already examples of conservation and research patronage undertaken by the tourism industry, motivated by the business reasons of investment protection and marketability, and they keep increasing throughout the world. However, no country or regionincluding the heritage regions of Mundo Maya, Silk Road, and Vaka Moana-has yet launched a strategy to systematically implement the tourism-destination partnership. 
A national or regional strategy that strives to fashion heritage tourism into the engine of a viable economy must be realistic about the visitor volume that can be generated by both the scope and the goal of such a strategy. The emphasis for accommodation and interpretive infrastructures, at the level of a country or a region, must be on planning, design, and management solutions that will transform the volume of visitors into a resource for conservation and sustainable development, while effectively zoning tourists through experienced management. A national or regional master plan that adopts these principles would acquire the capacity to attract tourism and hotel projects that could deliver what the industry now endorses as the formula for high-quality, high-profitability tourism: namely, environmental and cultural sensitivity (Shundich 1996).

I claim that ecotourism is the new direction in which all heritageoriented tourism will have to embark if it is to become prosperous and competitive in the twenty-first century. Natural, cultural, and archaeological tourism divide heritage tourism according to the specific character of the heritage resource or according to the special interests of travellers. Ecotourism is a value-based term that stresses the mutual interdependence of heritage conservation and sustainable valuation in the quality of the experience. The location or the type of the heritage resource that supports the ecotourism experience should be secondary. As a value-based term, ecotourism should also bring together the natural and cultural dimensions that are closely interwoven, both in the tourists' interests and interests of maintaining the spiritual, conservation, and research importance of many heritage attractions.

\section{Vaka Moana: beyond the world decade}

According to its guiding principles, the Vaka Moana program has been launched in response to the Pacific people's growing awareness of the need to maintain and further develop their heritage, and to promote economic development that will be based on the conservation and careful use of the region's resources. These principles could equally well be used to define the optimum course for leading South Pacific tourism into the century in which the winning strategy is the ability to compete globally while nourishing resources that are meaningful locally. This convergence of goals is a compelling reason for fashioning Vaka Moana into a flagship project for the continuation of the World Decade within the framework of regional development strategies. 
This argument is also persuasive because of the scope and seriousness of the concerns it addresses. While great importance has been attached by Pacific island governments to service-sector activities, led by tourism, the island countries lack the capital to develop tourism infrastructures and products (Hall 1994). The network of protected areas across the region is only rudimentary, considering the diversity and uniqueness of the region's heritage, and it is ill-funded. It is beyond the financial and human resource capabilities of existing agencies to deal with the very large number of areas that deserve immediate attention for their conservation value (Tourism Council of the South Pacific 1990). A conservation strategy that seeks to remedy the current situation will have to fully engage the beliefs, values, and activities of the Pacific island cultures that have been associated with the island environments for thousands of years, and whose lifestyles continue to be based on the land and the sea (Helu-Thaman 1992). No region matches the South Pacific island region in its potential for shattering ecotourism's narrow definition as nature travel. The national and regional benefits of the South Pacific tourism industry will depend on the ability of heritage tourism to appreciate, and alert the visitor to the blurring of natural and human ecology in the unique setting of each island ecosystem. This appreciation must be underscored by economic incentives directed at the local communities and conditioned on the sustainable utilisation of both the islands and their marine environs. Further, nowhere there is a more urgent need than in the South Pacific to pool the region's resources and aspirations to make tourism a long-term contributor to the individual countries' well-being. This island region must establish itself as a heritage destination in its own right in order to combat the physical remoteness of the South Pacific islands from the major tourist-generating markets of Europe and North America. It must take on the predominantly multi-destination mode of long-haul leisure travel that becomes the rule in heritage tourism, and recognise the need to mitigate against the relatively high cost of travel to the region through the product's quality, complexity, and immunity to imitation.

Vaka Moana possesses an outstanding potential to become the unifying theme and the source of a strong identity, appeal, and propensity to grow for the regional tourism strategy, which, in turn, would become the main sponsor and executor of the interdisciplinary, intercultural, and inter-agency mission of Vaka Moana. However, such a strategy will only be suitable, and economically sound, for the South 
Pacific island region if it is devised as a tourism-cum-conservation strategy that systematically enhances cultural integrity and crosscultural understanding. The ecological and cultural fitness of such a strategy will also be conditioned on its ability to shift from 'raw material' to 'value-added material' of the region's heritage product.

The common premise in heritage tourism is that the natural and cultural attractions ('raw material') exist and that tourism development means very much what it meant before, that is, adding infrastructure to accommodate the tourists and generating employment in servicing the tourists. Yet a tourism strategy centred around heritage experiences creates novel economic opportunities for making conservation profitable, for revitalising local traditions in concert with present-day needs, and for advancing research into multiple fields dealing with natural and cultural resources.

I identify three core steps of the value-adding process, in the context of creating a master-plan for heritage tourism. The first step is to define the multi-layered dimension of the destination's heritage. A site's heritage can often be connected with natural and cultural themes that are meaningful within the size of a country, or even a region. It might go back in time and link tangible attractions to intangible legends or beliefs. Therefore heritage product development should be approached as a dynamic process in which cooperation is essential. Heritage themes do not just enhance the complexity and interest of the tourist. They are valuable tools of cross-reference for a destination that will entice return visits, that will make naturally or culturally sensitive areas an integral part of the heritage experience with no excursion traffic, and that will provide a channel for spreading tourismgenerated benefits-particularly those of conservation sponsorshipbeyond areas that are suitable for tourist visits.

The second step is to equip the heritage resources with conservation guarantees. The tourism and hotel industry has a solid business reason to invest in conservation to make it effective in protecting the attractions that are now vital to the tourist enterprise. To maintain its investment, the industry needs the support of a proactive and well-enforced conservation strategy. I would argue that the global megatrend of heritage tourism creates an unprecedented opportunity-particularly in developing countries-for launching and sustaining national and regional conservation strategies, with the backing of the tourism and hotel industry's investment in management. 
The third step is to make provisions for continuous diversification and upgrading of the heritage experience. In heritage tourism, the experience of the heritage resources is the central pillar of tourism. The heritage experience is, in turn, catalysed by interpretation. A forward-looking plan for experience management should identify universities and research institutes willing to share the knowledge they advance about the natural and cultural resources in return for funding for future research, and invite indigenous people to share their cultural knowledge regarding reciprocal benefits from the tourism industry. This would offer long-term protection of the uniqueness and educational value of the heritage product.

It is in implementing these three steps that the cross-sectoral benefit, long-term success, and sustainability of heritage tourism will be decided for any country that makes the development of this industry a national priority. A tourism-conservation-research master plan I developed in concept for Panama illustrates this argument (Ayala 1997). It is within this three-step process of value-adding that Vaka Moana could be transformed into the propeller for the tourismdriven economy of the South Pacific islands in the twenty-first century.

\section{Defining the multi-layered dimension of the South Pacific heritage}

The South Pacific island region has had difficulty connecting with the international boom in leisure travel. Much of the blame is put on the airlines that tend to overfly the traditional stop-overs, and on the competition from new resorts in Queensland, South East Asia, and elsewhere (Bywater 1989). I would place at least as much blame on the homogenised image of 'paradise,' echoed by many of the South Pacific islands and their resorts, making these tourist island paradises mutually interchangeable and not so different from tropical paradises much closer to home. Reversing this image is a precondition of the viability of the national and regional tourism industries in the South Pacific.

The region's outstanding cultural diversity is being increasingly discovered by tourism marketing, although little of this 'discovery' is reflected in tourism planning. What has remained virtually overlooked in bringing tourism to the South Pacific economy is the daunting diversity of the island ecosystems within individual countries and across the region. Focusing just on the islands of eastern 
Fiji, a 1974 pilot project co-sponsored by UNESCO, the United Nations Fund for Population Activities (UNFPA) and the government of Fiji, disclosed remarkable ecological diversity within the traditional categories of high-volcanic and low-lying islands (UNESCO/UNFPA 1983). A follow-up study called Fiji an 'ecological theatre' since it alone exhibits many of the different stages of evolution in the South Pacific islands (Bayliss-Smith et al. 1988).

Webs of evolutionary, ecological, and cultural linkages of outstanding conservation and research importance pervade the South Pacific island ecosystem and are definable and meaningful on a multiplicity of spatial levels throughout the region. They lend themselves to the development of heritage themes that would alert the world, and the region itself, to the South Pacific's one-of-a-kind heritage identity that encompasses multiple heritage assets worthy of the World Heritage recognition. My own field research leads me to claim that Fiji's natural heritage alone comprises examples that, together, could measure up to all four categories of criteria used by UNESCO to determine natural sites for the World Heritage List. Yet, as of June 1997, neither Fiji nor any other South Pacific island country featured a single World Heritage Site.

The multi-layered valuation of the region's heritage according to themes would also allow the richness of cultural associations that envelop many island ecosystems to be addressed, in both tourism and conservation planning. A landscape that conforms to the definition of a natural landscape in its physical features, is more often than not a cultural landscape in the South Pacific, in view of its ties to the indigenous people's identity. It embodies the term 'associative cultural landscapes,' that UNESCO has chosen for the newest category of the World Heritage Sites, 'justifiable by virtue of the powerful religious, artistic, or cultural associations of the natural element rather than material cultural evidence, which may be insignificant or even absent' (Rossler 1994). This is a category that deserves prominence in establishing the region's World Heritage values because it connects landscapes and seascapes of superlative natural beauty and interest to the spiritual life of the South Pacific peoples.

I propose that the criteria for identifying World Heritage Sites be further broadened. Two or more sites, regardless of their 'natural,' 'cultural,' or 'associative cultural landscape' classification, could share World Heritage recognition on the basis of the evolutionary, ecological, or cultural relationships that bond them together and that are integral 
parts of their heritage value. The South Pacific island region is uniquely endowed to pioneer this concept of sites based on themes, which would introduce a dynamic dimension into recognition by World Heritage and would stimulate the spirit of cooperation that is at the heart of UNESCO's mandate.

The concept of multi-layered, cross-national valuation of heritage resources in the context of developing regional foundations for heritage tourism, resonates with Vaka Moana's goal of reinforcing the links between Pacific peoples through a better knowledge of their common characteristics. It results in economic ramifications for this and the related goal of involving all peoples of the various island countries of the Pacific Ocean, including those from non-independent countries.

\section{Equipping the region's heritage resources with conservation guarantees}

Global analyses now suggest that the fast rate at which entire habitats-from reefs to tropical forests-are being destroyed is becoming more important for determining risks of extinction than the present rarity of a species (Sisk et al. 1994). These findings are also relevant to the South Pacific island region. Estimates suggest that, at the current rate of log extraction and exportation, Papua New Guinea's timber will last only ten years more. Similarly, all reserves of lowland rainforest in the Solomon islands will be exhausted in less than a decade (Wallace 1996).

As Trevor Sofield (1992) states, though environmentalists have condemned logging operations, they have offered only idealism without cash. The solutions must be realistic about the region's development needs and be aware of the cultural and ecological clash between the western-style concept of a national park and the intimate relationship between the activities and lifestyles of the South Pacific peoples and their countries' natural environment. If ecotourism is to become the industry that makes the environment worth conserving, while promoting sustainable development, it has to generate a monetary benefit for the land-owning groups that outweighs the short-term financial gains from logging and other unsound land uses (Young 1992).

Conservation must become an integral part of a nation's entire development process, but that can only happen if the South Pacific governments and land-owners cease equating ecotourism with small 
budget, small scale, rough-it tourism. The reality is that all heritageoriented tourism is evolving into ecotourism, very rapidly in the field of marketing and steadily in respect of planning. In both marketing and planning, the driving force is the great marketability of the ecotourism philosophy; in the latter, the driving force is also the business imperative of protecting and enhancing heritage attractions to ensure quality and immunity to competition.

A thematic, multi-layered disclosure of the outstanding diversity of the region's heritage is the foundation for bringing conservation and development into a partnership. It offers a platform for a bold step the South Pacific island countries could take jointly by making conservation patronage a passport for all incoming tourism and hotel projects. The high profile that conservation sponsorship increasingly carries in the international tourism and hotel industry also encourages the use of regional heritage themes as instruments for extending the sponsorship benefits to places that are currently disadvantaged in their ability to attract tourism but that possess heritage resources of global significance. For example, while the occurrence of violence and diseases, such as malaria, hinders tourism development in parts of Melanesia, it does not mitigate against the prestige that the patron of the relevant countries' outstanding heritage would receive in any part of the region.

The effectiveness of this approach would correlate directly with the consistency of its implementation. This, in turn, needs a serious commitment by the governments to programs of public awareness, education, and, importantly, a network of tourism and conservation authorities at both the national and regional levels. In an economic perspective that is based on heritage tourism, the objective of the Tourism Council of the South Pacific (TCSP) is to foster regional cooperation in the development and promotion of tourism which is inseparable from the conservation goals of the South Pacific Regional Environment Program (SPREP) and the South Pacific Biodiversity Conservation Program (SPBCP). This claim can be supported by studies already undertaken within the region that appeal to the TSCP and SPREP to increase their contacts for mutual benefit (Tourism Council of the South Pacific 1990:3). Other studies point out that, despite the $\mathrm{SPBCP}$ 's regionally-defined mandate, its program activities have been largely site-specific and further hampered in their effectiveness by a lack of support for biodiversity conservation from local communities (Reti 1995). 
Developing the foundations of a tourism industry that derives momentum from the heritage resources, must include the economic foundations of conservation. Conservation of natural resources, but also cultural conservation that would motivate indigenous and local people to keep their sociocultural systems alive and evolving. In the South Pacific, the natural and cultural integrity of potential ecotourism sites depends on provision for sustainable utilisation by the Pacific islanders of the ecosystems with which they are bonded through ecology or association.

Fortunately, there is a planning-management model at hand: UNESCO's biosphere reserve. The value of the model is in its emphasis on integrating conservation with the promotion of scientific knowledge, skills, and the human values needed to support sustainable development. The 'Seville Strategy,' resulting from the 1995 International Conference on Biosphere Reserves in Seville, has further enhanced the desirability of introducing the biosphere reserve concept throughout the South Pacific. The Seville Strategy's emphasises the 'human dimension' of biosphere reserves that brings together cultural and biological diversity within the inter-generational perspective of benefits of sustainable development (UNESCO 1996).

In the South Pacific, I recommend delimiting areas that contain multiple heritage cores interrelated by heritage themes of national and regional significance for UNESCO's recognition as biosphere reserves. All of the region's future World Heritage Sites should be among those cores. Such a multi-layered approach to biosphere reserve development across the region would be conducive to mobilising the region's human capacity to foster sustainable development through cooperation, while paying tribute to the region's ecological and cultural complexity. As of now, Atoll de Taiaro in French Polynesia is the only biosphere reserve in the South Pacific island region.

The thematic approach addresses the priority that UNESCO's Man and the Biosphere program (MAB) now gives to consolidating the networks of biosphere reserves. It proposes an original solution to accomplishing a shift from specific sites to larger territories, and a possible scenario for setting up what the MAB program has coined 'regional units of sustainable development' (Azcarate 1993). Azcarate notes that putting in place such units will also imply recourse to new economic mechanisms, notably financial ones (1993:21). This is where underwriting the regional strategy of sustainable development by a regional tourism-cum-conservation strategy carries financial security. 
And this is where Vaka Moana's goal of resource conservation for the benefit of the peoples of the region can be reinforced by a business perspective on development without eroding the region's cultural identity.

\section{Providing for diversification and upgrading of the heritage experience in the region}

The Seville Strategy assigns great importance to the role of biosphere reserves in developing two sets of knowledge: one based on scientific research and supported by monitoring, training, and education, the other based on popular knowledge. When used in a complementary fashion, these two sets offer a powerful tool for achieving and managing sustainable development, particularly suitable for many island countries (UNESCO 1994). Simultaneous development and integration of these two sets of knowledge is also a priority concern for heritage tourism, particularly in the South Pacific where the quality of tourism needs to be addressed urgently. A complex interweaving of shared values linking people to the land, the skies, and the sea (Helu-Thaman 1992:27), makes conservation and accessibility of the time-tested knowledge of indigenous people indispensable for the hidden spiritual dimension of the region's heritage incorporated into the tourist experience. The diversity of the region's nature and culture, the high degree of endemism, the intricacy and complexity of bonds-some of which have unparalleled evolutionary and ecological significance-within and between the natural and human ecosystems, make modern research crucial for the valuation of the region's heritage through heritage tourism.

Knowledge may well be the single most persuasive reason for bonding the tourism-destination partnership across the South Pacific island region, on the basis of reciprocity of benefits. The industry's business motivation to invest in a knowledge-mobilising partnership is strong, given that the complexity, authenticity, and educational value of the tourist experience are at stake-the very qualities that progressively drive international leisure travel.

Interpretation, through which both sets of knowledge will be channelled into the heritage product, can also serve as an effective zoning tool. The idea of zoning is integral to the biosphere reserve concept, and is increasingly used in managing national parks and other protected areas world-wide. However, the way in which tourism has been brought into the zones buffering the protected cores has not 
been very successful in reconciling the number of tourists with the goals of conservation and sustainable development. The confinement of accommodations, particularly of larger hotels and resorts, to a zone outside nature reserves, World Heritage Sites, and other types of protected areas, is typically controlled by the consideration of the least intrusive or the least undesirable location for development that can service the incoming visitors. The accommodation facilities of the outer zone are expected to send their guests to inner zones to participate in ecotourism experiences (Ashton 1991).

The boom in heritage tourism makes this premise increasingly unsustainable and one that threatens, by sheer numbers, the integrity of the sensitive inner zones. In order to delimit and develop the zone to accommodate the bulk of the tourism, infrastructure ought to seek to maximise opportunities for interpretation-mediated contextual access at the expense of physical access (Ayala 1996b). The foremost objective ought to be to enhance the zone's capacity to retain the bulk of the visitors, without compromising the quality of the heritage experience. Consequently, views accessible from any prospective development site, combining scenic and interpretive qualities, should be given as much attention as the site's carrying capacity for the infrastructural projects, since the views will greatly condition the site's capacity for the management of the experience. Maximising contextual access and minimising physical access is the formula for tourism development that adheres to the spirit of the Seville Strategy. It fits the island region where success and sustainability of the tourism-driven economy are dependent on tourism's ability to bring the region's many superlative-but ecologically and culturally highly-sensitiveecosystems under the umbrella of a heritage product, without subjecting them to tourist traffic.

I have already developed the concept in a greater detail for Fiji, with a special emphasis on developing a master plan for the growth of Fiji's resort industry to become a catalyst for Fiji's heritage product (Ayala 1995b, 1995c). Fiji has an important role to play in activating the region's transformation into a flagship heritage destination, because of its already established position as a gateway country to South Pacific tourism, and as the main seat of the University of the South Pacific. I view and treat the University in my proposal as the main stakeholder in developing the indigenous modern-knowledge partnership under the auspices of heritage tourism (Ayala 1995a:44). 


\section{The road ahead}

The South Pacific island region must have a clear, cross-nationally endorsed action plan for heritage valuation in order to capitalise on the tourism and hotel industry's business interest in investing in the management of tourist experiences. This would conserve heritage resources, spread the tourism-generated benefit to the grass roots level, and help sponsor research. It will best serve the region if characterised by hierarchy and synergy. Hierarchy not in a political sense, but in the sense of highlighting the evolutionary and ecological bonds among the region's heritage resources, and their cumulative value for tourism, conservation, and research. Synergy should yield an alignment of commitments to natural and cultural conservation, and bridge the goals set for conservation and development.

Heritage themes, defined-with help of existing knowledge of the region, traditional as well as modern-on multiple spatial scales within and across the South Pacific island countries will provide the platform for bringing tourism, conservation, and sustainable development into an alliance. The thematic assessment of the region's heritage will back a thematic development of the region's conservation network, as well as proposals for the World Heritage recognition of the South Pacific's most remarkable heritage assets. The establishment of 'staging areas' will catalyse tourism planning in parallel with conservation planning that will be meaningful not only in the spatial sense but also, and primarily, as settings capable of supporting interpretation-mediated heritage experiences that cover much greater areas than tourists will visit. This will allow ecologically and culturally sensitive island environments to be set aside in a systematic fashion and region-wide, without depriving them of the benefits the tourism and hotel industry. An invitation for a prestigious sponsorship of the heritage attractions within both direct and contextual access will introduce each staging area to the investors. Where the biosphere reserve approach is applied, and either honoured by UNESCO's recognition or just used as a planning-management concept, the staging areas will become parts of the outer zones and executors of the biosphere reserve concept at the level of experience management and its funding. Since the implementation of the biosphere reserve concept will echo the thematic, multi-layered structure of the tourism-cumconservation strategy, it will also facilitate the achievement of Vaka Moana's goal of promoting widely disseminating all forms knowledge, both traditional and scientific across the region. 
Vaka Moana has been conceived and carried out as an ongoing program seeking the recognition of cultural, spiritual, and social values in the development process. It is this dynamic quality that places Vaka Moana in the heart of an economic development strategy that must continuously nourish the region's unique cultural identity if it is to triumph through heritage tourism.

\section{References}

Ashton, R., 1991. 'Trend and problems in ecotourism', in Proceedings of the 1991 World Congress on Adventure Travel and Eco-Tourism, The Adventure Travel Society, Englewood:22-31.

Ashton, R.E. and Ashton, P.S., 1993. An Introduction to Sustainable Tourism (Ecotourism) in Central America, USAID, Regional Office for Central American Programs, Guatemala City.

Ayala, H., 1995a. 'Ecoresort: a 'green' master plan for the international resort industry', International Journal of Hospitality Management, 14 (3/4):351-74.

— $1995 \mathrm{~b}$. 'The international resort industry, heritage conservation and sustainable development: towards an unprecedented partnership', Insula - International Journal of Island Affairs, 4(1):3247.

, 1995c. 'From quality product to ecoproduct: will Fiji set a precedent?', Tourism Management, 16(1):39-47.

— 1996a. 'Resort ecotourism: a paradigm for the 21st century', The Cornell Hotel and Restaurant Administration Quarterly, 37(5):46-53.

_ _ 1996b. 'Resort ecotourism: a master plan for experience management', The Cornell Hotel and Restaurant Administration Quarterly, 37(5):54-61.

_ 1997. 'Resort ecotourism: a catalyst for national and regional partnerships', The Cornell Hotel and Restaurant Administration Quarterly, 38(4):34-45.

Azcarate, T., 1993. Speech published in The Biosphere Conference: 25 years later, UNESCO, Paris:18-21.

Bayliss-Smith, T., Bedford, R., Brookfield, H., and Latham, M., 1988. Islands, Islanders and the World, Cambridge University Press, Cambridge.

Bookman, S., 1994. 'Perspective on ecotourism in island development', Insula-International Journal of Island Affairs, 3(1):19-21. 
Bywater, M., 1989. 'The Pacific islands', International Tourism Reports, 4:70-99.

Hall, C.M., 1994. 'Ecotourism in Australia, New Zealand and the South Pacific: appropriate tourism or a new form of ecological imperialism?', in E. Cater and G. Lowman (eds), Ecotourism: A Sustainable Option? John Wiley, Chichester:137-57.

Helu-Thaman, K., 1992. 'Ecocultural tourism: a personal view for maintaining cultural integrity in ecotourism development', in J.E. Hay (ed.), Ecotourism Business in the Pacific: promoting a sustainable experience, Environmental Science, University of Auckland, Auckland:24-29.

Reti, I., 1995. 'The South Pacific biodiversity conservation program', K.R. Miller and S.M. Lanou (eds), National Biodiversity Planning: guidelines based on early experiences around the world, World Resources Institute, Washington, DC:125-27.

Rossler, M., 1994. 'Tongariro: first cultural landscape on the World Heritage list', The World Heritage Newsletter, 4:15.

Shundich, S., 1996. 'Ecoresorts: dollars, sense and the environment', Hotels, 30(3):34-40.

Sisk, T.D., Launer, A.E., Switky, K.R., and Erlich, P.R. 1994. 'Identifying extinction threats', BioScience, 44(9):592-604.

Sofield, T., 1991. 'Sustainable ethnic tourism in the South Pacific: some principles', Journal of Tourism Studies, 2(1):56-72.

— 1992. 'The Guadalcanal track ecotourism project in the Solomon Islands', J.E. Hay (ed.), Ecotourism Business in the Pacific: promoting a sustainable experience, Environmental Science, University of Auckland, Auckland:89-100.

Tang, M., 1991. 'Evaluation of the tourist resources of the northern Silk Road, Xinjiang', Chinese Journal of Arid Land Research, 4(4):329-37.

Tourism Council of the South Pacific, 1990. Guidelines for the Integration Of Tourism Development And Environmental Protection in the South Pacific, Suva.

UNESCO, 1994. Island Agenda: an overview of UNESCO's work on island environments, territories and societies, UNESCO, Paris.

_ 1996. Biosphere Reserves: the Seville strategy and the statutory framework of the world network, UNESCO, Paris.

UNESCO/UNFPA, 1983. The Eastern Islands of Fiji- a study of the natural environment, its use and man's influence on its evolution, Orstom, Paris. 
Wallace, C.P., 1996. 'Pacific paradox: isles in despair', Los Angeles Times, March 16:A1, A34, A35.

World Tourism Organisation News, 1994. 'The Silk Road: creating a new tourism destination', 5:2-3.

Young, M., 1992. 'Ecotourism-profitable conservation', in J.E. Hay (ed.), Ecotourism Business in the Pacific: promoting a sustainable experience, Environmental Science, University of Auckland, Auckland:55-60. 